\section{Aortic Valve Replacement}

Replacement of the aortic valve with a homograft was introduced by D. N. Ross ${ }^{1}$ and both he and D. G. Barratt-Boyes and his colleagues ${ }^{2}$ have shown this technique to be clinically valuable. Homografts are of perfect design and have ideal central flow characteristics ; furthermore they have the unquestionable advantage of avoiding the hazard of embolization inherent in mechanical valve prostheses. Improvements in the design of prostheses, however, have considerably reduced the incidence of embolism and of failure of the ball, though patients given mechanical valves still require carefully controlled and continuous anticoagulant therapy. This in itself carries dangers, particularly in underdeveloped countries.

After an initial period of cautious observation other surgeons, particularly in the United States, have begun to use homograft valves. ${ }^{3} 4$ At the recent meeting of the American College of Surgeons in Chicago there was much discussion of this subject, with particular reference to methods of valve sterilization and storage, since late failures ${ }^{5}$ and calcification in the cusps ${ }^{6}$ have been reported in homografts after some years of use. At present many centres favour valves sterilized by irradiation, while others prefer the use of living valves. It has been suggested ${ }^{7}$ that in dogs freeze-dried valves are less subject to late degeneration and calcification than are fresh valves.

Difficulty in collecting homografts in some countries has led to the use of heterograft aortic valves collected from sheep and calves. J. P. Binet and his colleagues ${ }^{8}$ still use calf heterograft valves stored in a mercurochrome solution, which both sterilizes the valve and preserves the dead collagenous skeleton. In Australia M. F. O'Brien and his colleagues ${ }^{9}$ have enthusiastically adopted both pig and calf heterografts as a source of aortic valves for transplantation, using buffered formalin as a sterilizing and preserving medium. They have reported a series of 23 patients, of whom 20 are alive, with clinical evidence of regurgitation in only one.

So the mechanical effectiveness of dead homo- and heterograft valves is established, but attention is now being directed to the late results with particular attention to failure and calcification. Factors inducing calcification in the body are complex, and in this respect a recent article by $M$. R. Urist and J. M. Adams ${ }^{10}$ has an important bearing. They showed that in aortic segments transferred to the anterior chamber of the eye in rats the factors that affected calcification included age, the degree of development of the elastica, and a number of physical and chemical properties of the graft. The use of young aortic segments or suitable pre-treatment of the homografts could reverse the tendency to calcification-all of which opens up further promising fields for research.

\footnotetext{
' Ross, D. N., Lancet, 1962, 2, 487

Barratt-Boyes, B. G., Lowe, J. B., Cole, D. S., and Kelly, D. T. Thorax, 1965, 20, 495.

Hoeksema, T. D., Titus, J. L., Giuliani, E. R., and Kirklin, J. W. Circulation, 1967, 35, Suppl. No. 1, p. 9.

Bigelow, W. G., Yao, J. K., Aldridge H. E., Heimbecker, R. O., and Murray, G. D. W., f. thorac. cardiovasc. Surg., 1964, 48, 333.

Smith, J. C., Thorax, 1967, 22, 114.

Ross, D. N., Brit. F. Surg., 1967, 54, 842.

Duran, C. M. G., and Whitehead, R., ibid., 1966, 53, 1049.

Binet, J. P., Duran, C. G., Carpentier, A., and Langlois, J., Lancet, 1965. 2, 1275 .

- O'Brien, M. F., Clarebrough, J. K., McDonald, I. G., Hale, G. S. Bray, H. S., and Cade, J. F., Thorax, 1967, 22, 387

Urist, M. R., and Adams, J. M., Ann. Surg., 1967, 166, 1.

1 Halseth, W. L., Nellis N., Fraser, R. E., Thompson, R. G., and

Paton, B. C., Arch. Surg., 1967, 94, 750.'

Pan, B. C., Kwong, K.-H., Clark,

is Kwong, K.-H., Paton, B. C., and Hill, R. B., F. thorac. cardiovasc. Surg., 1967, 54, 199.

14 Ross, D. N., Lancet, 1967, 2, 956.
}

It has been argued that the use of living valve grafts removes the hazard of late degeneration. Unfortunately the living heterograft valve is immunologically active and subject to rejection ${ }^{11}{ }^{12}$ - which immediately introduces the complications of long-term immunosuppressive therapy. ${ }^{13}$ Living homografts, on the other hand, like the cornea, appear to be immunologically privileged ; but supplies of living homograft valves cannot possibly meet the demand for aortic valve replacement. The heavily calcified valves found in patients who come to operation are the end result of deposition of calcium in living congenitally bicuspid aortic valves. Other factors such as abnormal turbulence and trauma in the region of the bicuspid valve have also to be considered. Ross ${ }^{14}$ has reported the use of living pulmonary autografts in the aortic area-a technique designed to combine the virtues of a fresh living autograft with a non-obstructive and non-embolizing valve. However, if dead homografts and heterografts can be pretreated satisfactorily to prevent late degeneration, or if they can be procured under sterile conditions and stored for long periods in a viable state, they may meet the need for longterm replacement in the aortic area as an alternative to mechanical prostheses.

\section{Prescription Charges}

Fears that the allocations for hospital building would be cut in the Government's economies have proved unfounded. For this mercy there should be much thanks. Devaluation will have its effect on building costs, and that and inflation, which it seems is likely to go on, will continue to gnaw at the heart of planned expenditure. Progress in the provision of health centres by local authorities must also be affected. But at least there are to be no lethal excisions.

The medical profession as a whole cannot object to the reimposition of prescription charges. Subject to provision for hardship, it has been B.M.A. policy since 1964 that there should be charges. ${ }^{1}$ It was believed that they protected doctors from unnecessary work, and the great increase in the number of prescriptions after the charges were removed in February 1965 supported this belief. ${ }^{2}$ But a charge of 2s. $6 \mathrm{~d}$. per item could cause hardship in some cases, and the Government's wish to alleviate it is to be welcomed. The difficulties lie in identifying hardship and in the practicability of providing relief where it is needed.

The B.M.A.'s General Medical Services Committee is to help the Minister of Health in trying to find workable solutions to these difficulties (see Supplement, page 24). But the Committee is right to stress that it is the Government's job to identify those patients it wishes to exempt from the charges. The doctor-patient relationship should not be strained by making doctors arbiters of who should pay a levy. The 3,000 or so rural practitioners who dispense found collecting prescription money from patients invidious, and it is to be hoped that some other system can be devised. Selective charges as a means of increasing the resources of the Health Service must surely come. It would be a pity if they got a bad name because of the lack of thought given in the present case to the question of how to simplify the machinery for making exemptions.

\footnotetext{
1 Brit. med. 7. Suppl., 1964, 2, 75.

Ibid., 1965, 2, 164.
} 